R. M. Shahroze ${ }^{1}$, M. Chandrasekar ${ }^{*}$, K. Senthilkumar ${ }^{3,4}$, T. Senthil Muthu Kumar ${ }^{3,4}$, M. R. Ishak ${ }^{1,5}$, N. Rajini ${ }^{3}$, Suchart Siengchin ${ }^{4}$, S. O. Ismail ${ }^{6}$

${ }^{1}$ Department of Aerospace Engineering, Faculty of Engineering, University Putra Malaysia, Serdang, Selangor, Malaysia

${ }^{2}$ School of Aeronautical Sciences, Hindustan Institute of Technology \& Science, Padur, Kelambakkam, Chennai, Tamil Nadu, India

${ }^{3}$ Department of Mechanical Engineering, Kalasalingam Academy of Research and Education, Krishnankoil, Tamil Nadu, India

${ }^{4}$ Department of Materials and Production Engineering, The Sirindhorn International Thai-German Graduate School of Engineering (TGGS), King Mongkut's University of Technology North Bangkok, Bangsue, Bangkok, Thailand

${ }^{5}$ Aerospace Malaysia Research Centre (AMRC), Faculty of Engineering, Universiti Putra Malaysia, Serdang, Selangor, Malaysia

${ }^{6}$ Manufacturing, Materials, Biomedical and Civil Division, School of Engineering and Computer Science, University of

Hertfordshire, Hatfield, Hertfordshire, UK

\title{
Mechanical, Interfacial and Thermal Properties of Silica Aerogel-Infused Flax/Epoxy Composites
}

The mechanical, interfacial and thermal properties of a flax/ epoxy composite incorporated with a silica aerogel (SA) at $0.5,1.0$ and $2.0 \mathrm{wt} . \%$ were examined in this work. A set of maximum enhancements of $8.7 \%, 9.0 \%$ and $24.0 \%$ in the impact, inter-laminar shear strength (ILSS) and compressive strengths were achieved by adding $0.5 \mathrm{wt} . \%$ SA into the flax/epoxy composites. Also, the results obtained from dynamic mechanical analysis (DMA) indicated that the damping characteristics, peak tan delta and peak loss modulus improved at all filler concentrations, while the glass transition temperature $\left(T_{g}\right)$ decreased slightly. Features of SA such as biodegradability, ability to improve the mechanical properties as observed in this work and enhanced damping characteristics make them suitable for application in machine parts requiring impact resistance and vibration damping characteristics.

\section{Introduction}

Composite materials reinforced with plant fibres, known as bio-composites have emerged as an eco-friendly alternative to the conventional composites reinforced with synthetic fibres (Thiagamani et al., 2019; Rangappa et al., 2020). However, the bio-composites are yet to establish themselves in a wide range of applications due to their inferior mechanical, thermal and physical properties when compared to the composites reinforced with synthetic fibres (Haq et al., 2008). The performance of the natural fibre-reinforced composites can be significantly improved by adding a small quantity of fillers to the resin (Njuguna et al., 2008). Some of the commercially available fillers include carbon nanotubes (single and multi-walled), nanoclays, graphene and layered silicates (Shahroze et al.,

\footnotetext{
* Mail address: Muthukumar Chandrasekar, School of Aeronautical Sciences, Hindustan Institute of Technology \& Science, Padur, Kelambakkam, Chennai - 603103, Tamil Nadu, India E-mail: chandrasekar.25j@gmail.com
}

2018). Studies on the effect of filler inclusion on the mechani$\mathrm{cal}$, thermal and morphological properties of flax reinforced polymer composites have been reported. Maximum flexural strength and toughness have been obtained for flax/geopolymer composite with $2.0 \mathrm{wt} \%$ nanoclay (Assaedi et al., 2016a). Alumina nanoparticles infused into the flax/epoxy composite were observed to have better storage modulus and higher creep resistance (Siengchin et al., 2013). Flax/poly-lactic acid composites with $2.5 \mathrm{wt} \%$ montmorillonite clay (MMT) showed a higher storage modulus and tensile properties (Kumar et al., 2010). In a different study, Suchart indicated that thermal stability of the flax/high-density polyethylene composite was improved due to the addition of silicon dioxide nanoparticles (Siengchin, 2012).

Silica aerogel (SA) is a relatively new filler material developed in the last few decades. It is derived from the colloidal form of rice husk. SA used in this study has a trademark name "Maerogel" and has advantages over the conventional aerogels. In terms of synthesis, Maerogel involves the use of a non-hazardous extraction process compared to the hazardous process using chemicals for conventional SA. Maerogel also has a mesoporous structure with a high specific area, low density and higher thermal insulation properties than the conventional SA which are attractive features of an additive (Kencana n.d.). Thus, it has been selected as filler for the present study.

SA extracted from the rice husk was used as filler in the kenaf/epoxy (Bajuri et al. 2016), flax/geopolymer composites (Assaedi et al., 2016b) and carbon nanotubes - silica aerogel (CNT-SA)-epoxy nanocomposites (Mazlan et al., 2015). Mixing SA with the resin resulted in significant improvement of various properties of composites. The optimum concentration at which the maximum enhancement occurs depends on the properties examined. To date, silica nanoparticles, also known as silica aerogel (SA) has not been used as filler with the flax/ epoxy composite, hence their properties remain unexplored.

Therefore, this work aims at investigating the influence of SA on the mechanical, interfacial and thermal properties of the flax/epoxy composite through compression, impact, short beam test and dynamic mechanic analysis. 


\section{Experimental Procedure}

\subsection{Materials}

Biotex flax fibres in a unidirectional tape form were purchased from Easycomposites, Staffordshire, UK. Epoxy resin (D.E.R. Epoxy 331) with 905-3S joint amine type hardener were procured from MZI supplies, Kuala Lumpur, Malaysia, and SA synthesised from rice husk was supplied by Maerotech Sdn Bhd, Kuala Lumpur, Malaysia. Material specifications of flax, epoxy and SA are tabulated in Table 1.

\subsection{Preparation of Composite Specimens}

The flax/epoxy composite without silica aerogel, designated as FE, while the composite infused with SA is designated as SFE, was prepared by hot press moulding. The resin was mixed with aerogel at different weight \% (as shown in Table 2), using the mechanical stirrer at $500 \mathrm{~min}^{-1}$ for $30 \mathrm{~min}$. Silica aerogel was added slowly into the resin during the stirring process to ensure their uniform distribution within the resin. Initially, the mould was sprayed with a release agent for easy removal of composites after fabrication. Then, the aerogel infused resin was mixed with hardener at ratio $2: 1$ and poured on the fibres, which were laid at $\left[0^{\circ} / 90^{\circ} / 0^{\circ} / 90^{\circ}\right]_{\mathrm{s}}$ orientation. The resin mixture was allowed to settle within the fibre layers and the setup was placed in the hot press and pressed at $105^{\circ} \mathrm{C}$ for $10 \mathrm{~min}$ under $20 \mathrm{MPa}$ pressure.

\subsection{Characterisation}

\subsubsection{Dynamic Mechanical Analysis}

The dynamic mechanical analysis was carried out on specimens with dimensions of $60 \times 12.5 \times 4 \mathrm{~mm}^{3}$, using a dynamic mechanical analyser (model DMA/SDTA861e, Mettler Toledo, Bangkok, Thailand). The test was conducted in dual cantilever mode $25^{\circ} \mathrm{C}$ to $150{ }^{\circ} \mathrm{C}$ at a frequency of $1 \mathrm{~Hz}$, with a constant load of $3 \mathrm{~N}$ and displacement amplitude of $10 \mu \mathrm{m}$. The heating rate was maintained at $3{ }^{\circ} \mathrm{C} / \mathrm{min}$ under nitrogen atmosphere.

\subsubsection{Impact Test}

Impact strength of the composites was determined from the Izod impact test. The test was carried out according to the ASTM D256 (ASTM 2010a), using HIT5.5P impact testing machine (Zwick/Roell, Bangkok, Thailand). Five identical specimens, each specimen with dimensions of $100 \times 10 \times 4 \mathrm{~mm}^{3}$, were tested and the average results were reported.

\subsubsection{Short Beam Test}

A short beam test was performed in accordance with the ASTM D2344 standard on 5 composite specimens of size $40 \times 12 \times 4 \mathrm{~mm}^{3}$ and the average results were reported (ASTM 2000). The specimen was loaded in a Instron 3365 (Instron, Bangkok, Thailand) of $5 \mathrm{kN}$ capacity. The machine had a support span of $24 \mathrm{~mm}$ and the cross head displacement speed was set to $1.27 \mathrm{~mm} / \mathrm{min}$. The maximum force recorded

\begin{tabular}{|c|c|c|}
\hline Material & Parameters & Specification \\
\hline Flax & Density $\left(\mathrm{g} / \mathrm{cm}^{3}\right)$ & 1.5 \\
& Fibre diameter $(\mu \mathrm{m})$ & $500-800$ \\
& Tensile strength $(\mathrm{MPa})$ & 50 \\
& Young's modulus $(\mathrm{GPa})$ & 1.16 \\
D.E.R Epoxy 331 & Density $\left(\mathrm{g} / \mathrm{cm}^{3}\right)$ & 57 \\
& Tensile strength $(\mathrm{MPa})$ & - \\
& Young's modulus $(\mathrm{GPa})$ & 0.03 \\
& Density (g/cm $\left.{ }^{3}\right)$ & 900 \\
& Specific surface area (m $/ \mathrm{g})$ & $20-50$ \\
& Size (nm) & 1700 \\
\hline
\end{tabular}

Table 1. Specifications of flax, epoxy and silica aerogel (Chandrasekar et al., 2019; Shahroze et al., 2019)

\begin{tabular}{|c|c|c|c|}
\hline Notation & $\begin{array}{l}\text { Fibre } \\
\text { wt. } \%\end{array}$ & $\begin{array}{l}\text { Resin } \\
\text { wt. } \%\end{array}$ \\
\hline FE & 30 & 70.0 & - \\
0.5\% SFE & 30 & 69.5 & 0.5 \\
1.0\% SFE & 30 & 69.0 & 1.0 \\
$2.0 \%$ SFE & 30 & 68.0 & 2.0 \\
\hline
\end{tabular}

Table 2. Formulation, compositions of the composites and the notations used 
from the user interface was used to calculate the inter-laminar shear strength (ILSS), using Eq. 1.

$\mathrm{ILSS}=\frac{3 \mathrm{P}}{4 \mathrm{bh}}$,

where $\mathrm{P}$ represents the maximum load $(\mathrm{N}), \mathrm{b}$ and $\mathrm{h}$ denote the width and thickness of the specimen $(\mathrm{mm})$, respectively, and ILSS was measured in MPa.

\subsubsection{Compression Test}

Compression test was carried out on a Instron 3382 (Instron, Bangkok, Thailand) in accordance to the ASTM D695 (ASTM 2010b). A specimen with the dimensions of $20 \times 20 \times 4 \mathrm{~mm}^{3}$ was loaded between the discs, and a compressive force was applied at the crosshead speed of $1.5 \mathrm{~mm} / \mathrm{min}$. The average compressive strength and modulus of 5 specimens were reported.

\subsubsection{Fractography}

The failure behavior of the fractured specimens after the compression test was examined using a scanning electron microscope (SEM, model S-3400N, Hitachi, Bangkok, Thailand). Prior to the examination of the specimens, they were subjected to gold sputtering to enhance conductivity.

\section{Results and Discussion}

\subsection{Dynamic Mechanical Analysis}

\subsubsection{Storage Modulus}

The viscoelastic properties of the flax/epoxy composites were examined by varying the silica aerogel concentrations using the dynamic mechanical analysis technique. The variation in storage modulus ( $\left.\mathrm{E}^{\prime}\right)$ as a function of temperature with different loadings of silica aerogel in flax/epoxy composites is presented in Fig. 1.

In the glassy region, the storage modulus of the composites was not closer to each other and the stiffness of these composites was affected at lower temperatures, especially at $1.0 \mathrm{wt} . \%$ and 2.0 wt. $\%$ of silica aerogel-based composites. The improvement of storage modulus of these composites followed the order: $1.0 \% \mathrm{SFE}>2.0 \% \mathrm{SFE}>\mathrm{FE}>0.5 \%$ SFE. Moreover, it can be observed that there was no significant difference in the $\mathrm{E}^{\prime}$ values of 2.0 wt.\% of SA-based composites when compared with the pure or non-SA composite. A higher concentration of SA caused uneven distribution and resulted in reduced storage modulus relative to the composites with $1.0 \mathrm{wt} \%$ of SA. All the types of composites presented a gradual decrease in the value of $\mathrm{E}^{\prime}$ with an increase in temperature (above $70^{\circ} \mathrm{C}$ ), whereas the $1.0 \mathrm{wt} \%$ of SA-based composites had a sharp fall in $\mathrm{E}^{\prime}$. It has been reported that an increase in temperature causes an increase in the molecular mobility of the polymer chains, which conversely decreases the $E^{\prime}$ (Hameed et al., 2007). In the transition region, the $\mathrm{E}^{\prime}$ of composites embedded with SA exhibited lesser values of $\mathrm{E}^{\prime}$, when compared with the non-SA composites. In the rubbery region, the storage moduli of all the composites were close to each other. From the results obtained, it was evident that the infusion of SA did not influence the storage moduli of the composites. A similar observation was reported on date palm fibre/ epoxy composites (Gheith et al., 2019).

\subsubsection{Loss Modulus}

Loss modulus $\left(\mathrm{E}^{\prime \prime}\right)$ is the measure of energy dissipated as heat per cycle under deformation. It is the viscous response of the material. It is also related to the friction between the particles within the composites, which responds for the molecular movements, relaxation processes and other structural homogeneities (Jawaid et al., 2016). The variations in the loss modulus as a function of temperature with respect to the varying concentrations of SA are presented in Fig. 2.

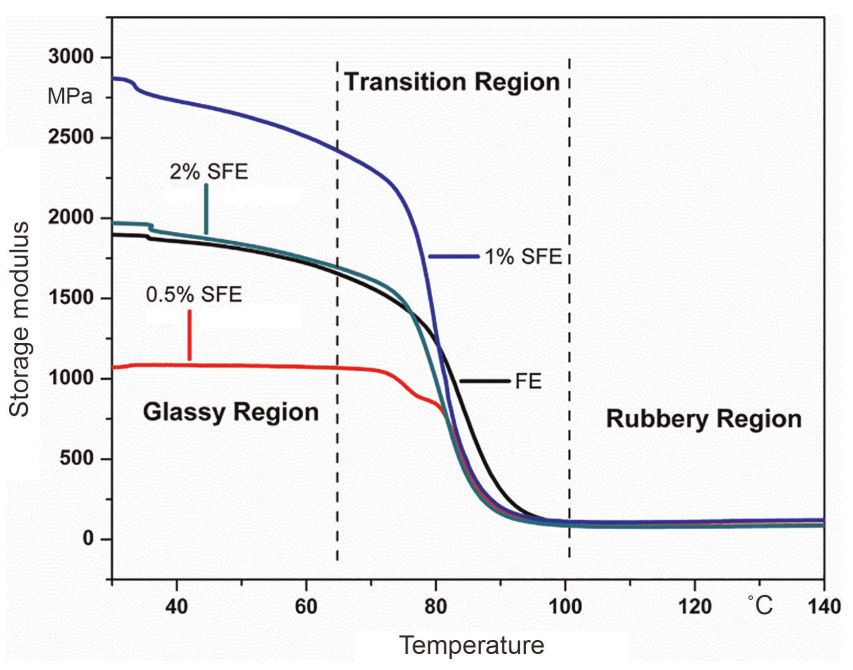

Fig. 1. Storage modulus of the FE and SFE composites

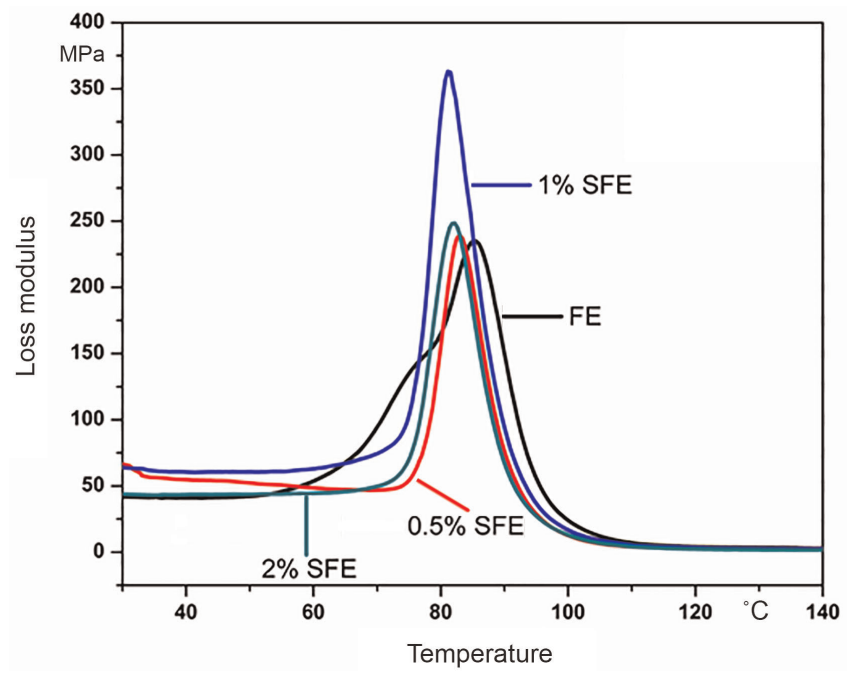

Fig. 2. Loss modulus of the FE and SFE composites 
From Fig. 2, it is evident that the SA composites followed a similar behavior. As the storage modulus was increased, it reached a maximum value before it decreased with an increase in temperature. It can be observed that the differences in loss moduli of the flax/epoxy composites, composites with $0.5 \%$ and $2.0 \%$ of silica aerogel were marginal. But, the flax/epoxy composites with $1.0 \%$ of silica aerogel exhibited the highest value of loss modulus. This could be due to the restriction of the molecular mobility of the polymer by the disordered SA particles. Consequently, it resulted in higher interactions between the components and higher internal friction. Therefore, it enhanced the energy dissipation, thus causing the highest loss modulus (Hameed et al., 2007; Jawaid et al., 2016). It is also observed that the peak values of the SA-based composites shifted to lower temperatures when compared with the pure composites. The peak values of loss moduli, the corresponding $\mathrm{T}_{\mathrm{g}}$ values and their changes with respect to the SA addition are presented in Table 3.

\subsubsection{Damping Parameter}

The damping parameter $(\tan \delta)$ is the ratio between the loss and the storage modulus. It is also called as the mechanical loss factor. It has been reported that damping was influenced by the incorporation of fillers, their distribution and the matrix filler interaction. Therefore, as temperature increased, the damping went through a maximum in the transition region and decreased in the rubbery region (Mallarino et al., 2009). Furthermore, the $\tan \delta$ peak position and height indicated the structure and properties of the composite material. The variation in the damping parameters as a function of temperature with respect to the varying concentrations of silica aerogel is presented in Fig. 3.

From Fig. 3, it is evident that the SA-infused composites exhibited higher peak when compared to the non-SA composites in the transition region. However, there were $\mathrm{T}_{\mathrm{g}}$ values at lower temperatures corresponding to the peaks. Moreover, it can be observed that there was only a very minimal widening of the peaks. Based on this, it was expected that the composites have only a minimum time for the relaxation of molecules. The peak values of $\tan \delta$ and the corresponding $\mathrm{T}_{\mathrm{g}}$ values are presented in Table 4.

From the dynamic mechanical analysis, it was observed that the load bearing capacity of the SA-infused composites was expectedly higher, when compared with the pure matrix. Also, the SA-based composites exhibited an improvement in the damping characteristics, but the $\mathrm{T}_{\mathrm{g}}$ values showed some reduced thermal effects of the filler.

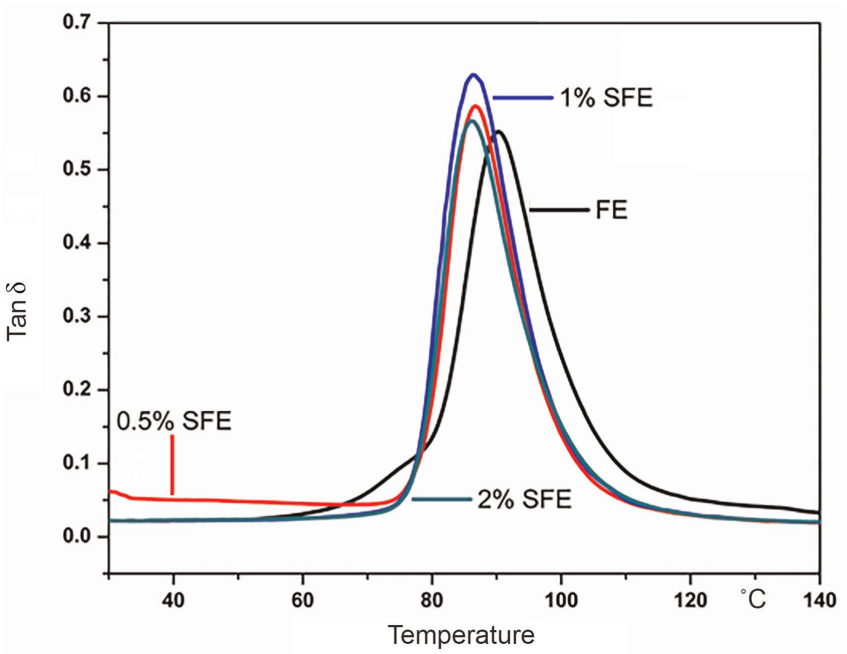

Fig. 3. Tan $\delta$ vs. time plot for the FE composites with varying concentrations of $S A$

\begin{tabular}{|c|c|c|c|c|}
\hline Composite & $\begin{array}{c}\text { Peak value } \\
\mathrm{MPa}\end{array}$ & $\begin{array}{c}\text { Change } \\
\%\end{array}$ & $\begin{array}{c}\mathrm{Tg} \\
\mathrm{C}\end{array}$ & $\begin{array}{c}\text { Change } \\
\%\end{array}$ \\
\hline FE & 234.97 & 0 & 85.51 & 0 \\
$0.5 \% \mathrm{SFE}$ & 239.32 & 1.85 & 82.92 & 3.02 \\
$1.0 \% \mathrm{SFE}$ & 363.06 & 54.52 & 81.08 & 5.18 \\
$2.0 \% \mathrm{SFE}$ & 248.43 & 5.73 & 82.19 & 3.88 \\
\hline
\end{tabular}

Table 3. Changes in peak loss moduli and their corresponding glass transition temperatures

\begin{tabular}{|c|c|c|c|c|}
\hline Composite & Peak value of tan $\delta$ & $\begin{array}{c}\text { Change } \\
\%\end{array}$ & $\begin{array}{c}\mathrm{T}_{\mathrm{g}} \\
{ }^{\circ}\end{array}$ & $\begin{array}{c}\text { Change } \\
\%\end{array}$ \\
\hline FE & 0.552 & 0 & 90.24 & 0 \\
$0.5 \%$ SFE & 0.586 & 6.16 & 86.72 & 3.90 \\
$1.0 \%$ SFE & 0.629 & 13.95 & 86.20 & 4.47 \\
2.0\% SFE & 0.566 & 2.53 & 86.06 & 4.03 \\
\hline
\end{tabular}

Table 4. Changes in peak tan $\delta$ values and their corresponding glass transition temperatures 


\subsection{Impact Strength}

The filler addition affects the impact energy absorbing capacity of a composite (Shahroze et al., 2018). Therefore, the addition of SA and its effects on the impact strength of FE was investigated using Izod impact test. The results obtained are depicted in Fig. 4. It was observed that addition of SA to the flax/epoxy composites enhanced and decreased their impact strength, as a threshold or optimal value being obtained with $0.5 \%$ SFE composite specimen, as shown in Fig. 4.

It can be observed from Fig. 4 that an improvement in the impact strength was achieved with the infusion of SA in flax/ epoxy composites. At a low concentration, the improvement was comparatively higher. With $0.5 \%$ of SA in SFE composite, the impact strength was enhanced $8.7 \%$, while $1.0 \%$ of SA in similar SFE composite resulted in $8.20 \%$ improvement in impact strength. This occurrence was attributed to an increase in porosity of composites with an infusion of porous silica aerogel particles (Maghsoudi and Motahari, 2018). They further elaborated that the porous medium in a composite expanded the shock wave that was going through the composite, and hence, improved the impact strength. However, a higher concentration of $2.0 \%$ of SA showed a degrading effect and the strength reduced by almost $20 \%$, when compared to FE composite. This behavior can be attributed to the hydrophilic nature of the filler (Halimaton, 2011). The increased concentration of the fillers led to an increased weakness in the interfacial bond or strength within the composite's constituents. This phenomenon resultantly facilitated crack growth at lower

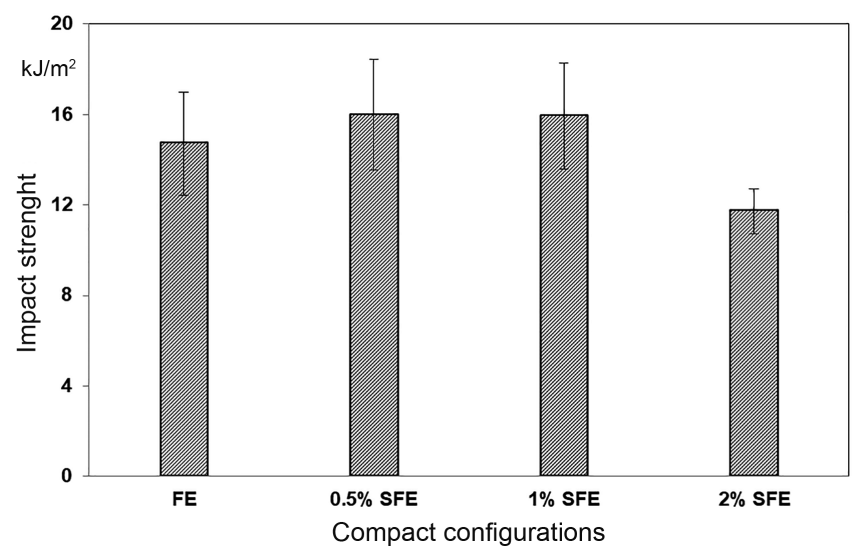

Fig. 4. Impact strength of the FE and SFE composites

\begin{tabular}{|c|c|}
\hline Composite & $\begin{array}{c}\text { Inter-laminar shear strength } \\
\mathrm{MPa}\end{array}$ \\
\hline $\mathrm{FE}$ & $9.73 \pm 0.81$ \\
$0.5 \% \mathrm{SFE}$ & $10.58 \pm 1.46$ \\
$1.0 \% \mathrm{SFE}$ & $10.16 \pm 0.65$ \\
$2.0 \% \mathrm{SFE}$ & $9.25 \pm 0.79$ \\
\hline
\end{tabular}

Table 5. Inter-laminar shear strength of the FE and SFE composites loads. Moreover, a higher concentration of fillers formed agglomerates, which led to a high-stress concentration site and, eventually, reduced the impact strength of fibre-reinforced composites (Khankrua et al., 2013).

\subsection{Inter-Laminar Shear Strength}

Figure 5 shows the picture of a fractured specimen from the short beam test. The ILSS was determined for the FE and SAinfused FE composites at various concentrations. The results obtained are presented in Table 5.

It can be observed that ILSS improved due to the incorporation of SA up to a threshold ILSS value of $10.16 \mathrm{MPa}$ at 1.0 wt. $\%$. Both $0.5 \%$ and $1.0 \%$ SFE composites exhibited $9 \%$ and $4.5 \%$ higher ILSS than the FE composite. This implied that the addition of up to $1.0 \mathrm{wt} \% \mathrm{SA}$ in the resin was helpful in achieving a better interfacial bond between the fibre and matrix. A recent study also reported higher ILSS at a certain concentration of a filler-infused flax/epoxy composite, due to a better fibre/matrix interfacial bond (Li et al., 2015). In general, SA dispersed in the resin provided a toughening effect to the matrix and strengthened the fibre/matrix interface such that the crack propagation was arrested and resulted in a superior performance of the composite. However, when 2.0 wt. $\%$ SA was added to the FE, ILSS decreased to 9.25 MPa, a $5 \%$ decrease when compared with the FE composite specimen, as early mentioned, agglomeration of fillers at a higher filler concentration could cause a premature failure at lower loads.

\subsection{Compressive Properties}

The compressive strength and modulus evaluated from the crushing test are presented in Table 6.

The SA-infused composites showed a better compressive strength than the FE composite. A nearly $24 \%, 18 \%$ and $4 \%$ enhancement in the strength were obtained with an addition of $0.5,1.0$ and 2.0 wt.\% SA into the FE composites, respectively, when compared with the non-SA FE composite. The increase in compressive modulus was not as prominent as the compressive strength. This showed that modulus is a fibre dependent property and the fibre orientation dominats their load bearing

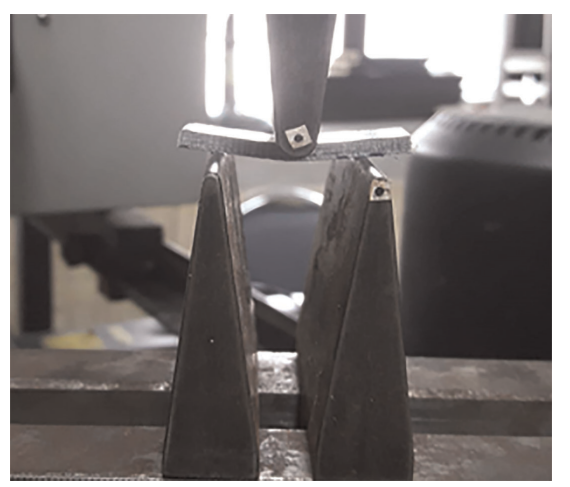

Fig. 5. The short beam test setup showing a fractured specimen 
ability. In the laminate with $\left[0^{\circ} / 90^{\circ} / 0^{\circ} / 90^{\circ}\right]_{\mathrm{s}}$ fibre orientation, the fibres oriented perpendicular to the loading direction were less effective. However, the matrix strengthening effect and enhanced fibre/matrix bond induced by the SA filler prolonged the failure, therefore resulting in a better compressive strength and modulus than that of the non-SA FE composite.

\subsubsection{Failure Behavior}

All the composite specimens subjected to compressive test failed due to micro buckling, delamination and fibre breakage in the loading direction as well as matrix cracking in the transverse direction, as shown in Fig. 6A and B and Fig. 7A and B. However, the $1.0 \mathrm{wt} . \%$ SFE composite specimen exhibited a large extent of delamination and multiple delamination damage, as depicted in Fig. 7A. On the other hand, the top view of the fractured specimen shown in Fig. 7B revealed the matrix

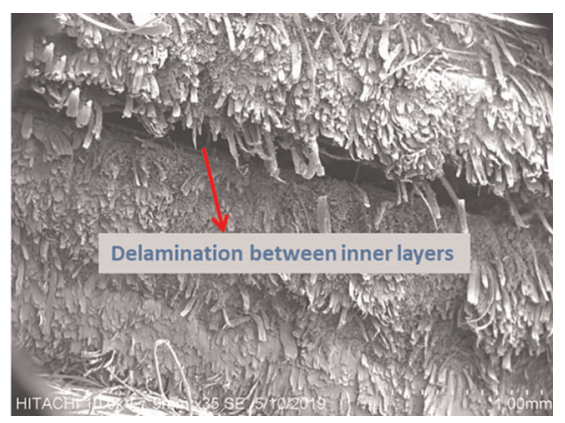

A)

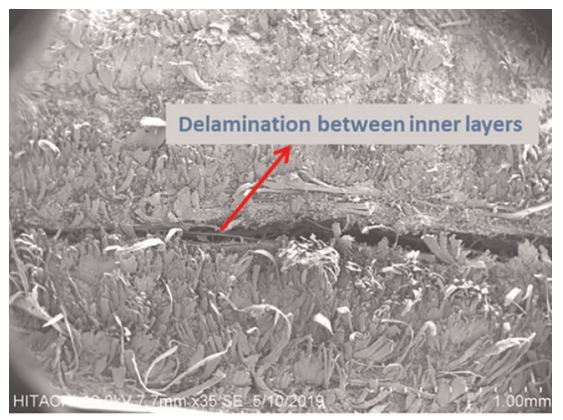

B)

Fig. 6. Delamination damage of the compressed (A) FE and (B) $0.5 \%$ SFE composite specimen cracking and multiple fibre breakage. Evidently, these micrographs further established that a higher concentration of SA in flax/epoxy composite weakened the interfacial bond between the fibre layers. This observation corroborates the decrease in material properties discussed in the previous sections.

\section{Conclusions}

The experimental investigation has shown that the flax/epoxy bio-composite exhibited best or optimal mechanical, interfacial properties and thermal stability with the addition of $1.0 \mathrm{wt} . \%$ SA. It was evident that the SA filler acted as a binding agent, improved the interfacial strength or bond between the fibre and the matrix. Hence, it enabled the composite to achieve superior properties. However, at $2.0 \mathrm{wt} . \%$ of SA, the performance of the composite in terms of impact strength and compression modulus was inferior, when compared with that of the non-SA filler com-

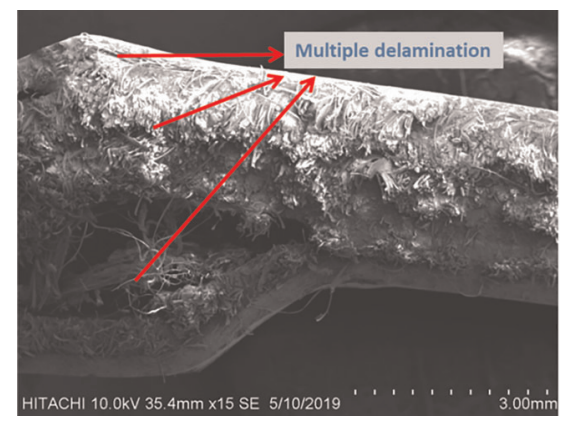

A)

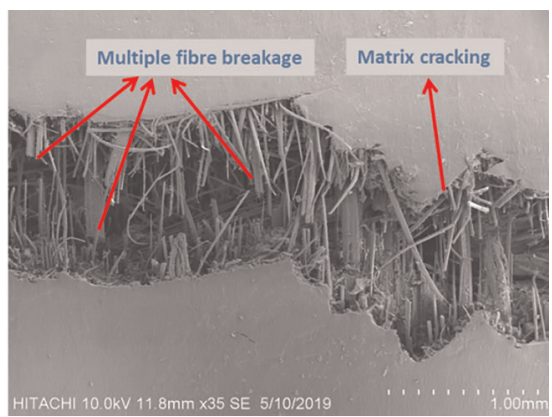

B)

Fig. 7. Failure/damage modes of the compressed (A) $1.0 \%$ SFE composite specimen and (B) $2.0 \%$ SFE composite specimen

\begin{tabular}{|c|c|c|}
\hline Composite & $\begin{array}{c}\text { Compressive strength } \\
\text { MPa }\end{array}$ & $\begin{array}{c}\text { Compressive modulus } \\
\text { MPa }\end{array}$ \\
\hline FE & $53.63 \pm 11.26$ & $2.09 \pm 0.14$ \\
$0.5 \%$ SFE & $66.36 \pm 9.38$ & $2.24 \pm 0.19$ \\
$2.0 \%$ SFE & $63.16 \pm 6.98$ & $2.18 \pm 0.21$ \\
$2.0 \%$ SFE & $55.99 \pm 12.04$ & $2.07 \pm 0.36$ \\
\hline
\end{tabular}

Table 6. Compressive strength and modulus of the FE and SFE composites 
posite. This implied that filler accumulation within the matrix at a higher concentration affected the stress transfer within the composite and has direct impact on the fibre/matrix bond. The minimum ILSS value of $9.25 \mathrm{MPa}$ obtained for the composite with 2.0 wt.\% SA further supported the degradation of fibre/matrix bond, due to the filler agglomeration at a high concentration. Lastly, delamination, micro buckling of fibres, fibre breakage and matrix cracking failure modes were observed in the composite specimens tested under a compressive loading.

\section{References}

Assaedi, H., Shaikh, F. U. A. and Low, I. M., "Characterizations of Flax Fabric Reinforced Nanoclay-Geopolymer Composites", Composites Part B, 95, 412-422 (2016),

DOI:10.1016/j.compositesb.2016.04.007

Assaedi, H., Shaikh, F. U. A., and Low, I. M., "Influence of Mixing Methods of Nano Silica on the Microstructural and Mechanical Properties of Flax Fabric Reinforced Geopolymer Composites", Const. Build. Mater., 123, 541-552 (2016),

DOI:10.1016/j.conbuildmat.2016.07.049

ASTM, D 2344, "Standard Test Method for Short-Beam Strength of Polymer Matrix Composite Materials and Their Laminates", American Society for Testing and Materials, West Conshohocken, PA (2000)

ASTM, D. "ASTM D 256-10, "Standard Test Methods for Determining the Izod Pendulum Impact Resistance of Plastics", American Society for Testing and Materials, West Conshohocken, PA (2010a)

ASTM, D 695, "Standard Test Method for Compressive Properties of Rigid Plastics", American Society for Testing and Materials, West Conshohocken, PA (2010b)

Bajuri, F., Mazlan, N., Ishak, M. R. and Imatomi, J., "Flexural and Compressive Properties of Hybrid Kenaf/Silica Nanoparticles in Epoxy Composite", Procedia Chem., 19, 955-960 (2016), DOI:10.1016/j.proche.2016.03.141

Chandrasekar, M., Shahroze, R. M., Ishak, M. R., Saba, N., Jawaid, M., Senthilkumar, K., Senthil Muthu Kumar, T. and Suchart Siengchin, "Flax and Sugar Palm Reinforced Epoxy Composites: Effect of Hybridizati on on Physical, Mechanical, Morphological and Dynamic Mechanical Properties", Mater. Res. Express, 6, 105331 (2019), DOI:10.1088/2053-1591/ab382c

Gheith, M. H., Aziz, M. A., Ghori, W., Saba, N., Asim, M., Jawaid, M. and Alothman, O. Y., "Flexural, Thermal and Dynamic Mechanical Properties of Date Palm Fibres Reinforced Epoxy Composites" J. Mater. Res. Technol., 8, 853-860 (2019), DOI:10.1016/j.jmrt.2018.06.013

Halimaton, H., U.S. Patent 7897 648, (2011)

Hameed, N., Sreekumar, P. A., Francis, B., Yang, W. and Thomas, S., "Morphology, Dynamic Mechanical and Thermal Studies on Poly(styrene-co-acrylonitrile) Modified Epoxy Resin/Glass Fibre Composites", Composites, Part A, 38, 2422-2432 (2007), DOI:10.1016/j.compositesa.2007.08.009

Haq, M., Burgueño, R., Mohanty, A. K. and Misra, M., "Hybrid BioBased Composites from Blends of Unsaturated Polyester and Soybean Oil Reinforced with Nanoclay and Natural Fibers", Compos. Sci. Technol., 68, 3344-3351 (2008),

DOI:10.1016/j.compscitech.2008.09.007

Jawaid, M., El Kacem Qaiss, A. and Bouhfid, R. (Eds.): Nanoclay Reinforced Polymer Composites: Natural Fibre/Nanoclay Hybrid Composites, Springer, Heidelberg, Berlin (2016), DOI:10.1007/978-981-10-0950-1

Kencana, Gelanggang, N. D., "Maerogel", http://maerogel.com/maerogel.html (2020)

Khankrua, R., Pivsa-Art, S., Hiroyuki, H. and Suttiruengwong, S. "Thermal and Mechanical Properties of Biodegradable Polyester/ Silica Nanocomposites", Energy Procedia, 34, 705-713 (2013), DOI:10.1016/j.egypro.2013.06.803

Kumar, R., Yakabu, M. K. and Anandjiwala, R. D., "Effect of Montmorillonite Clay on Flax Fabric Reinforced Poly Lactic Acid Composites with Amphiphilic Additives", Composites Part A, 41, 1620-1627 (2010), DOI:10.1016/j.compositesa.2010.07.012
Li, Y., Chen, C., Xu, J., Zhang, Z., Yuan, B. and Huang, X., "Improved Mechanical Properties of Carbon Nanotubes-Coated Flax Fiber Reinforced Composites", J. Mater. Sci., 50, 1117-1128 (2015), DOI:10.1007/s10853-014-8668-3

Maghsoudi, K., Motahari, S., "Mechanical, Thermal, and Hydrophobic Properties of Silica Aerogel-Epoxy Composites", J. Appl. Polym. Sci., 135, 45706 (2018), DOI:10.1002/app.45706

Mallarino, S., Chailan, J. F. and Vernet, J. L., "Interphase Study in Cyanate/Glass Fibre Composites Using Thermomechanical Analysis and Micro-Thermal Analysis", Compos. Sci. Technol., 69, $28-$ 32 (2009), DOI:10.1016/j.compscitech.2007.10.043

Mazlan, N., Termazi, N., Abdul Rashid, S. and Rahmanian, S., "Investigations on Composite Flexural Behaviour with Inclusi on of CNT Enhanced Silica Aerogel in Epoxy Nanocomposites", Appl. Mech. Mater., 695, 179-182 (2015), DOI:10.4028/www.scientific.net/AMM.695.179

Njuguna, J., Pielichowski, K. and Desai, S., "Nanofiller-Reinforced Polymer Nanocomposites", Polym. Adv. Technol., 19, 947-959 (2008), DOI:10.1002/pat.1074

Rangappa, S. M., Siengchin, S. and Dhakal, H. N., "Green-Composites: Ecofriendly and Sustainability", Appl. Sci. Eng. Progress, 13, 183 - 184 (2020), DOI:10.14416/j.asep.2020.06.001

Shahroze, R. M., Ishak, M. R., Sapuan, S. M., Leman, Z., Chandrasekar, M. and Asim, M. "Effect of Silica Aerogel Additive on Mechanical Properties of the Sugar Palm Fiber-Reinforced Polyester Composites", Int. J. Polym. Sci., Article ID 3978047 (2019), DOI: $10.1155 / 2019 / 3978047$

Shahroze, R. M., Ishak, M. R., Salit, M. S., Leman, Z., Asim, M. and Chandrasekar, M., "Effect of Organo-Modified Nanoclay on the Mechanical Properties of Sugar Palm Fiber-Reinforced Polyester Composites", Biores., 13, 7430-7444 (2018), https://ojs.cnr.ncsu.edu/ index.php/BioRes/article/view/BioRes_13_4_7430_Shahroze_Organo_ Modified_Nanoclay_Composites,

DOI:10.15376/biores.13.4.7430-7444

Siengchin, S., "Impact, Thermal and Mechanical Properties of High Density Polyethylene/Flax/SiO2 Composites: Effect of Flax Reinforcing Structures", J. Reinf. Plast. Compos., 31, 959-966 (2012), DOI: $10.1177 / 0731684412451333$

Siengchin, S., Pohl, T., Medina, L. and Mitschang, P., "Structure and Properties of Flax/Polylactide/Alumina Nanocomposites", J. Reinf. Plast. Compos., 32, 23-33 (2013), DOI: $10.1177 / 0731684412464586$

Thiagamani, Senthil Muthu Kumar, Senthilkumar Krishnasamy and Suchart Siengchin, "Challenges of Biodegradable Polymers: An Environmental Perspective", Appl. Sci. Eng. Progress, 12, 149 (2019), DOI:10.14416/j.asep.2019.03.002

\section{Acknowledgements}

The authors would like to thank Universiti Putra Malaysia, 43400 UPM Serdang, Selangor, Malaysia for their financial support through the grant IPS 9633800, and this research was also supported by King Mongkut's University of Technology North Bangkok (KMUTNB), Thailand through Grant No. KMUTNB64-KNOW-07.

Date received: March 13, 2020

Date accepted: July 21, 2020

Bibliography

DOI 10.1515/ipp-2020-3964

Intern. Polymer Processing XXXVI (2021) 1; page 53-59

(C) 2021 Walter de Gruyter GmbH, Berlin/Boston, Germany ISSN 0930-777X $\cdot 2195-8602$ 